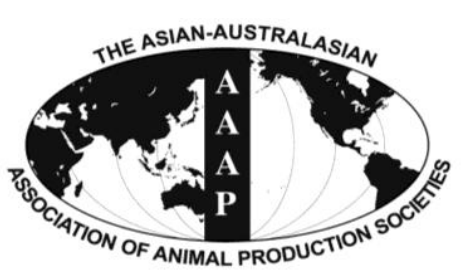

Open Access

Asian Australas. J. Anim. Sci.

Vol. 27 , No. $7:$ : 1044-1049 July 2014

http://dx.doi.org/10.5713/ajas.2012.12425

pISSN 1011-2367 elSSN 1976-5517

\title{
Effects of Light Color on Energy Expenditure and Behavior in Broiler Chickens
}

\author{
Nara Kim, Sang-rak Lee*, and Sang-Jin Lee ${ }^{1}$ \\ Department of Animal Science and Environment, Konkuk University, Seoul 143-701, Korea
}

\begin{abstract}
This study was conducted in order to investigate whether the presence of light or different colors of light would influence the energy expenditure and behavior of broiler chickens. Eight 8-week-old broiler chickens were adapted to a respiration chamber (Length, $28.5 \mathrm{~cm}$; Height, $38.5 \mathrm{~cm}$; Width, $44.0 \mathrm{~cm}$ ) for one week prior to the initiation of the experiment. In experiment 1 , energy expenditure and behavior of the chickens were analyzed in the presence or absence of light for four days. Chickens were exposed

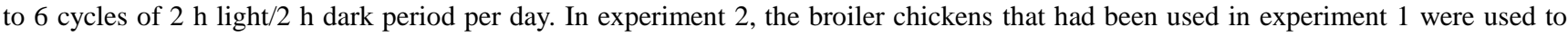
evaluate the effect of 4 different wavelength light-emitting diodes (LEDs) on the energy expenditure and behavior of broiler chickens. The LEDs used in this study had the following wavelength bands; white (control), red (618 to $635 \mathrm{~nm}$ ), green (515 to $530 \mathrm{~nm}$ ) and blue (450 to $470 \mathrm{~nm}$ ). The chickens were randomly exposed to a 2-h LED light in a random and sequential order per day for 3 days. Oxygen consumption and carbon dioxide production of the chickens were recorded using an open-circuit calorimeter system, and energy expenditure was calculated based on the collected data. The behavior of the chickens was analyzed based on following categories i.e., resting, standing, and pecking, and closed-circuit television was used to record these behavioral postures. The analysis of data from experiment 1 showed that the energy expenditure was higher $(\mathrm{p}<0.001)$ in chickens under light condition compared with those under dark condition. The chickens spent more time with pecking during a light period, but they frequently exhibited resting during a dark period. Experiment 2 showed that there was no significant difference in terms of energy expenditure and behavior based on the color of light (white, red, green, and blue) to which the chickens were exposed. In conclusion, the energy expenditure and behavior of broiler chickens were found to be strongly affected by the presence of light. On the other hand, there was no discernible difference in their energy expenditure and behavior of broiler chickens exposed to the different LED lights. (Key Words: Lighting Color, Energy Expenditure, Behavior, Calorimetry, Broiler Chicken)
\end{abstract}

\section{INTRODUCTION}

Interests in farm animal welfare have been increasing which accompanied by a similarly growing interest in companion animal welfare. However, there are currently few regulations relating to animal welfare in Korea compared to other regions of governance such as the European Union. Most domesticated animals intended for higher efficient productivity are reared with the artificial environments such as lighting, ventilation, and space.

\footnotetext{
* Corresponding Author: Sang-rak Lee. Tel: +82-2-450-3696, Fax: +82-2-458-2124, E-mail: leesr@konkuk.ac.kr

${ }^{1}$ Animal Plant and Fisheries Quarantine and Inspection Agency, Anyang 430-824, Korea.

Submitted Aug. 7, 2012; Revised Oct. 18, 2012; Accepted Apr. 2, 2014
}

Light, one of the most important environmental factors in determining animal behavior, influences animal's life cycles and controls their behavior to a great extent (Kristensen et al., 2007). Although it is known that lighting influences behavior, reproductive ability, and, more specifically, growth rates of poultry (Phillips and Piggins, 1992), livestock are still reared under different lighting conditions from that of nature and most livestock experience intense stress due to light intensity, wavelength, and photoperiod which tuned by human (Zulkifli et al., 1998).

It has been recently reported that the intensity, wavelength and light source influence the behavioral and physiological responses of birds (Kristensen et al., 2007). Most researches have focused on production traits and the 
light preferences (e.g. Wathes et el., 1982; Widowski et al., 1992; Prayitno et al., 1997; Kjær and Vestergaard, 1999; Kristensen et al., 2007; Son et al., 2009), however there are few studies explaining why the productivity and behavior of birds were closely associated with lighting condition. In addition, there have been no studies with broiler chickens albeit that there is an abundance of studies with laying hens.

Macleod et al. (1988) showed that calorimetry is a good way to directly measure the difference in energy expenditure through different conditions of light. And it has been reported that energy expenditure directly related to physical activity (Boshouwers and Nicaise, 1987; Macleod et al., 1988). The aim of this study is thus to investigate whether chickens' behavior as an indication of stress is associated with lighting condition. In addition, energy expenditure patterns by broiler chickens exposed to different lighting schedule were measured using an opencircuit calorimeter.

\section{MATERIALS AND METHODS}

\section{Animals and management}

In this study, eight 8-week-old male broiler chickens (ROSS breed) with an average weight of $2.76 \pm 0.06 \mathrm{~kg}$ were used. Each broiler chicken was introduced to an individual respiration chamber, equipped with a feeder and drinker. Prior to the experiment, the animals were allowed to adapt to the experimental environment for over one week. The experiment was performed twice.

All birds were fed ad libitum throughout the experimental period. Temperature and humidity inside the respiration chamber were maintained as $20 \pm 3^{\circ} \mathrm{C}$ and $55 \pm 5 \%$. The respiration chamber (width, $28.5 \mathrm{~cm}$; length, $38.5 \mathrm{~cm}$; height, $44 \mathrm{~cm}$ ) was thoroughly cleaned for one hour from 10:00 to 11:00 a.m. and was provided with new litter and feed every day. The photoperiod was $16 \mathrm{~h}$ Light and $8 \mathrm{~h}$ Dark and data were collected for 12 hours during lighting hours.

The intensity of the incandescent bulb at 240 lux was determined by an illuminometer (DT-1309, CEM, Shenzhen, China) at the height of the chickens' eye. The colors of light (white, red, green, and blue) were controlled by intensity controllers. All factors except for light were kept constant throughout the whole experiment.

The wavelengths of light selected were white (control), blue (short wavelength, 450 to $470 \mathrm{~nm}$ ), green (medium wavelength, 515 to $530 \mathrm{~nm}$ ) and red (long wavelength, 618 to $635 \mathrm{~nm}$ ). Light-emitting diodes (LED) lights (0530-10, Daz, Seongnam, Korea) were used for those purposes.

\section{Experimental design}

The present study was composed of two experiments. Experiment 1 was conducted to observe how light and dark can affect the energy expenditure and behavior of the chickens exposed to an alternating light (240 lux) and dark (0 lux) cycle, each photoperiod for every $2 \mathrm{~h}$ and lasted for $12 \mathrm{~h}$ per day (thus 6 cycles of light and dark period per day). Experiment 2 was conducted to observe how different colors of light affect the energy expenditure and behavior of the chickens. Four lightings with 2-h-long photoperiod per each light were alternated in a random order. All chickens were equally exposed three times per each light during 3 days.

The lighting system was controlled by a digital timer switch (HTS-AT10, Han seung, Daegu, Korea). Both experiments were conducted over $12 \mathrm{~h}$ (starting from 22:00 and finishing at 10:00) per day. Experiment 1 lasted for 4 days and experiment 2 lasted 3 days. Conditions and experimental methods were identical in both experiments except for the lighting conditions described above.

\section{Energy expenditure measurement}

Energy expenditure was measured by a respiration chamber system using an open-circuit calorimeter. The respiration chamber was made with transparent acrylic boards to observe behavior of the animals. The chamber contained two holes of $8 \mathrm{~mm}$ diameter, one of which (at the back) was connected with a rubber hose for air ventilation. The front hole was located $11 \mathrm{~cm}$ from the bottom of the chamber, and the back hole was $6 \mathrm{~cm}$ lower from the top of the chamber. The rubber hoses were filtered, and tightly secured so as to prevent leaks.

In this study, four vacuum pumps (AC0602-A1003-A, NITTO KOHKI Co., Ohta-ku, Japan) were used for ventilation. In addition, a system sample pump (Columbus Instruments, Columbus, OH, USA) during ventilation was used to obtain a gas sample, which was dried by a dehydrating agent (23001, W.A Hammond drierite company, Xenia, OH, USA) and subsequently transferred to an oxygen analyzer (Paramax-101, Columbus Instruments) and a carbon dioxide analyzer (VA-3000, Horiba Stec Co., Kyoto, Japan). Gas analyses were run over $24 \mathrm{~h}$. The flow in chamber was measured for each chamber by using four flow meters (GFM57, Aalborg Instruments \& Controls Inc., Orangeburg, NY, USA). The flow rate was set at $7 \mathrm{~L} / \mathrm{min}$ and controlled so that the maximum concentration of $\mathrm{CO}_{2}$ did not to exceed $0.5 \%$ (Klein and Wright, 2006).

The flow and oxygen data were collected through a data logger (Columbus Instruments, Columbus) every $90 \mathrm{~s}$. The data from the carbon dioxide gas analyzer was saved in a computer through software (VA-3000, Horiba Stec Co.). The leakage test was performed for the chamber throughout the entire system.

The energy expenditure in dynamic conditions was calculated by using the parameter of McLean and Tobin (1987) for the gas measured through the analyzers over the 
actual experimental time (22:00 to $10: 00)$. Then it was converted to $\mathrm{kJ}$ by using the following equation.

$\mathrm{EE}(\mathrm{kW})=-20.53\left(\mathrm{~V}_{\mathrm{o}}+\mathrm{Vd} / \mathrm{dt}\right) \Delta \mathrm{O}_{2}$

EE, energy expenditure

$\mathrm{V}$, volume of chamber $(\mathrm{L})$

$\mathrm{V}_{\mathrm{o}}$, amount of flow, ventilated amount $(\mathrm{L} / \mathrm{min})$

$\mathrm{Vd} / \mathrm{dt}$, oxygen consumption/concentration difference in oxygen - ventilated amount

$\Delta \mathrm{O}_{2}$, concentration difference between inlet and outlet $(\% / \mathrm{s})$

\section{Behavior observation}

Behavior of broiler chickens was consecutively observed for $24 \mathrm{~h}$ through closed-circuit television (Model: SLA 854C-M2085, Seongnam, Korea). Three main behavioral categories, i.e., pecking, standing and resting were identified following the criteria below and video footage was analyzed by sectioning it into $6 \mathrm{~min}$ frames for each animal.

In order to understand the differences in energy expenditure and behavior with each light treatment, the chickens' behavior was recorded while simultaneously measuring oxygen and carbon dioxide. In this study, three categories listed below were used while other behaviors such as feeding, drinking walking, preening, wingstretching, dust-bathing, and defecating were not counted.

Pecking: Behavior of pecking the floor or feathers

Standing: Behavior of standing still

Resting: Behavior of sitting on the litter without movements (i.e., stable status)

\section{Statistical analysis}

Individual chickens were considered as a replicate in experiments 1 and 2. Statistical analysis for significant differences within experiment 1 was performed by the paired t-test using the SAS program (SAS institute, 2002). The mean values of each individual broiler chicken in light and dark conditions were compared. Variance analysis of experiment 2 was performed using general linear model procedure and significant differences of each color of light were analyzed using Duncan's multiple range test (Duncan, 1955). The results were verified by setting independent variables for the color of light and dependent variables for energy expenditure and the time-budget value (expressed as appearance rate).

\section{RESULTS AND DISCUSSION}

Influence of light and dark conditions on energy expenditure (Experiment 1)

The difference in energy expenditure under light and

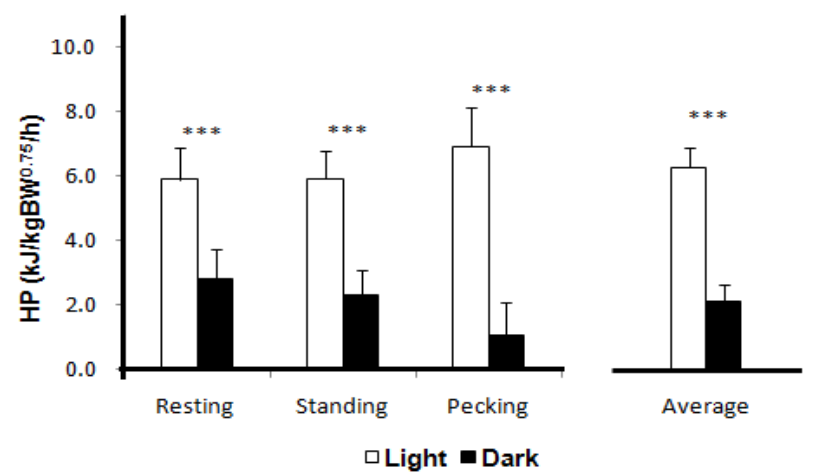

Figure 1. Energy expenditure of broiler chickens exposed to light and dark conditions for $2 \mathrm{~h}$. Asterisks indicate the statistically significant difference $(\mathrm{p}<0.001)$. HP, heat production; BW, body weight.

dark conditions is shown in Figure 1. The total mean value of energy expenditure was $6.25 \pm 0.60 \mathrm{~kJ} / \mathrm{kg} \mathrm{BW} \mathrm{BW}^{0.75} / \mathrm{h}$ and $2.08 \pm 0.54 \mathrm{~kJ} / \mathrm{kg} \mathrm{BW} \mathrm{BW}^{0.75} / \mathrm{h}$ for light or dark condition, respectively, indicating that the energy expenditure was significantly higher $(\mathrm{p}<0.001)$ in the light-exposed broiler chickens.

Energy expenditure when classified by the behavior type was also higher when the light was on. Particularly, energy expenditure of light-exposed broiler chickens during resting (an indicator of stable behavior) was $5.90 \pm 0.96$ $\mathrm{kJ} / \mathrm{kg} \mathrm{BW}^{0.75} / \mathrm{h}$ which is markedly higher $(\mathrm{p}<0.001)$ compared with that of dark-exposed counterparts $\left(2.83 \pm 0.88 \mathrm{~kJ} / \mathrm{kg} \quad \mathrm{BW}^{0.75} / \mathrm{h}\right)$. It implies that energy expenditure of broiler chickens became higher in the presence of light although they were in stable resting condition. The energy expenditures for both standing and pecking were also higher in the light-exposed chickens compared with the dark-exposed counterparts $(\mathrm{p}<0.001)$.

As revealed in experiment 1 , the energy expenditure is significantly different depending on the presence or absence of light. This explains why energy expenditure of broiler chickens varies when light is provided. Indeed, previous studies have shown that light and dark conditions influenced various performance or meat quality-related traits such as mortality rates (Classen et al., 1991; Riddell and Classen, 1992; Blair and Gardiner, 1993; Lott et al., 1996) and disease (Buckland et al., 1976; Classen and, 1991; Riddell and Classen, 1992) as well as feeding efficiency (Hooppaw and Goodman, 1976) and carcass quality (Malone et al., 1980). The question raised as to whether the difference in energy expenditure by light is related to the wavelength of light has been further evaluated in experiment 2 .

\section{Influence of light and dark conditions on animal behavior (Experiment 1)}

The difference in behavior of broiler chickens under 
light and dark conditions is shown in Figure 2. Resting behavior was predominant $(90.6 \pm 2.84 \%)$ in broiler chickens under dark conditions compared to light conditions, indicating that there was almost no movement in darkexposed broiler chickens $(\mathrm{p}<0.05)$. Broiler chickens exposed light $v s$. dark period tended $(\mathrm{p}>0.05)$ to exhibit more frequent standing behavior. In addition, broiler chickens significantly spent more time $(\mathrm{p}<0.05)$ in pecking during light period $(16.1 \pm 3.43 \%)$ compared with the dark period $(0.6 \pm 0.36 \%)$. In line with our study, Appleby et al. (1992) and Alvino et al. (2009) also reported that broiler chickens under high intensity light period tended to increase behavior types such as feather pecking, preening, foraging, and aggressive pecking.

\section{The influence of light colors on energy expenditure (Experiment 2)}

The difference in energy expenditure under different light colors is shown in Figure 3. The total mean value of energy expenditure is highest in green light $(8.54 \pm 0.69$ $\left.\mathrm{kJ} / \mathrm{kg} \mathrm{BW} \mathrm{BW}^{0.75} / \mathrm{h}\right)$, followed by red $(7.60 \pm 0.58 \mathrm{~kJ} / \mathrm{kg}$ $\left.\mathrm{BW}^{0.75} / \mathrm{h}\right)$, blue $\left(7.41 \pm 0.65 \mathrm{~kJ} / \mathrm{kg} \mathrm{BW}^{0.75} / \mathrm{h}\right)$, and white light $\left(7.26 \pm 0.58 \mathrm{~kJ} / \mathrm{kg} \mathrm{BW} \mathrm{BW}^{0.75} / \mathrm{h}\right)$, however there is no marked difference between light colors.

For resting, the energy expenditure of green lighting $\left(7.91 \pm 1.08 \mathrm{~kJ} / \mathrm{kg} \mathrm{BW} \mathrm{BW}^{0.75} / \mathrm{h}\right)$ was relatively higher $(\mathrm{p}>0.05)$ than the rest of lightings, as followed by red $(7.13 \pm 1.16$ $\left.\mathrm{kJ} / \mathrm{kg} \mathrm{BW}^{0.75} / \mathrm{h}\right)$, blue $\left(7.08 \pm 1.06 \mathrm{~kJ} / \mathrm{kg} \mathrm{BW}^{0.75} / \mathrm{h}\right)$, and white $\left(6.87 \pm 1.17 \mathrm{~kJ} / \mathrm{kg} \mathrm{BW} \mathrm{BW}^{0.75} / \mathrm{h}\right)$ lighting. This result may indicate that broiler chickens would feel more comfortable under the white or blue light in the current experimental setting which employed the relatively short-term (e.g., 3 day-duration) lighting schedule.

For standing, the energy expenditure of lighting was higher in the order of green $\left(8.73 \pm 1.09 \mathrm{~kJ} / \mathrm{kg} \mathrm{BW}^{0.75} / \mathrm{h}\right)$, red $\left(8.68 \pm 0.92 \mathrm{~kJ} / \mathrm{kg} \quad \mathrm{BW}^{0.75} / \mathrm{h}\right)$, blue $(8.40 \pm 1.09 \mathrm{~kJ} / \mathrm{kg}$ $\left.\mathrm{BW}^{0.75} / \mathrm{h}\right)$, and white $\left(7.94 \pm 1.24 \mathrm{~kJ} / \mathrm{kg} \mathrm{BW} \mathrm{BW}^{0.75} / \mathrm{h}\right)$ light, however there was no marked difference among the different light colors. For pecking, the energy expenditure

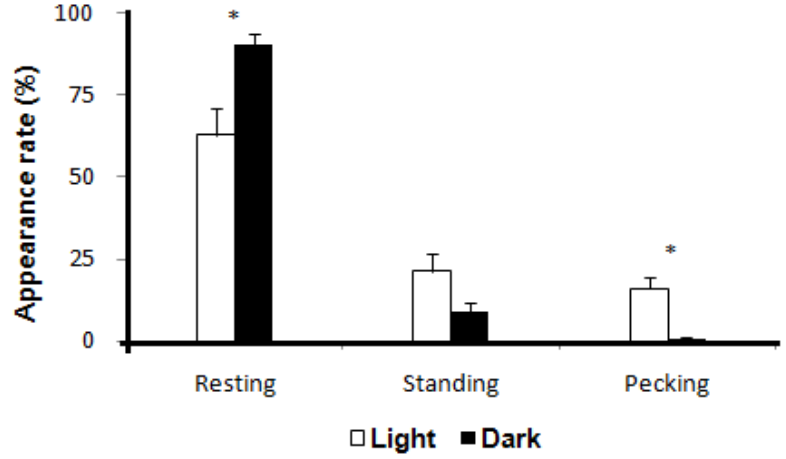

Figure 2. Behaviors of broiler chickens during $2 \mathrm{~h}$ exposure to light and dark. Asterisks indicate the statistically significant difference $(\mathrm{p}<0.001)$.

of lighting was in the order of green $(8.98 \pm 1.37 \mathrm{~kJ} / \mathrm{kg}$ $\left.\mathrm{BW}^{0.75} / \mathrm{h}\right)$, red $\left(6.99 \pm 0.72 \mathrm{~kJ} / \mathrm{kg} \mathrm{BW}^{0.75} / \mathrm{h}\right)$, white $(6.96 \pm 0.97$ $\left.\mathrm{kJ} / \mathrm{kg} \mathrm{BW}^{0.75} / \mathrm{h}\right)$, and blue $\left(6.75 \pm 1.13 \mathrm{~kJ} / \mathrm{kg} \mathrm{BW}^{0.75} / \mathrm{h}\right)$ lights, but the effect by light colors was not statistically different. It was shown that energy expenditure of broiler chickens exposed to different light colors was not different, indicating that broiler chickens may be not stressed under the current light color regimen. Our observation is in line with previous results (Kondra, 1961; Schumaier et al., 1968; Peterson and Espenshade, 1971; Wathes et al., 1982) that broiler chickens, turkeys and laying hens were not affected by the intensity and spectrum of light with respect to the laying or growth performance.

\section{The influence of light colors on animal behavior (Experiment 2)}

The difference in behavior of broiler chickens under different light colors is shown in Figure 4. Broiler chickens spent more time in resting under red light $(80.89 \pm 3.31 \%)$, followed by blue $(76.71 \pm 4.48 \%)$, green $(76.25 \pm 3.72 \%)$ and white $(77.28 \pm 4.21 \%)$. Although not statistical significance, broiler chickens exposed to red color exhibited frequent resting behavior than other colors, which may indicate their preference on red color. Contrary to our study, Prayitno et al.

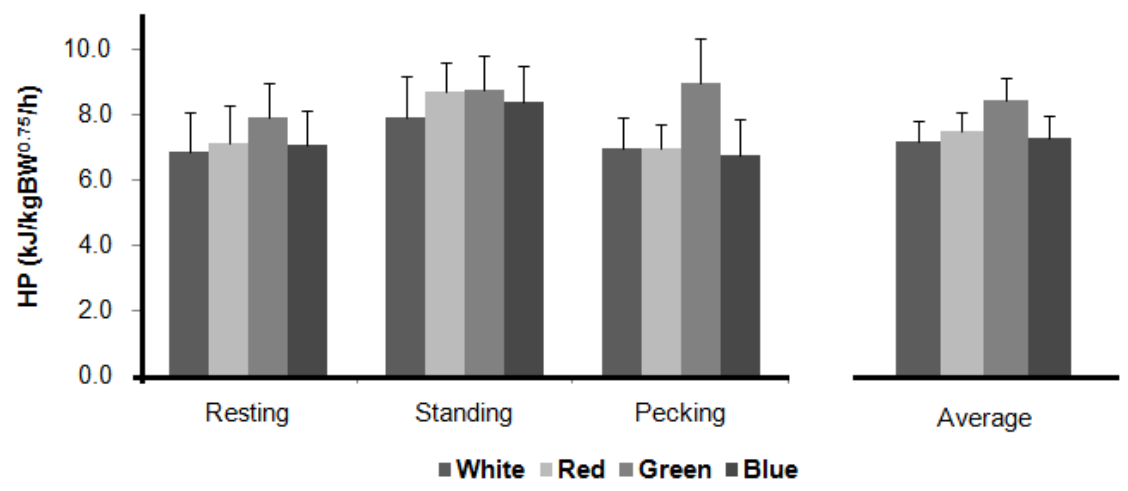

Figure 3. Energy expenditure of broiler chickens exposed to white, red, green or blue LED lights for $2 \mathrm{~h}$. HP, heat production; BW, body weight; LED, light-emitting diode. 


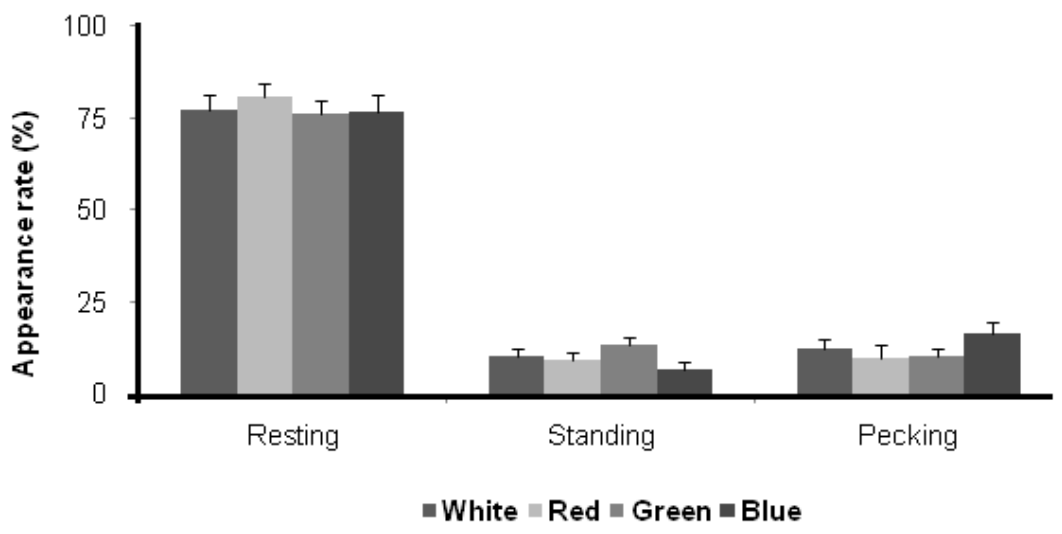

Figure 4. Behavior of broiler chickens exposed to white, red, green or blue LED lights for 2. LED, light-emitting diode.

(1997) reported that broiler chickens preferred blue or green over red or white lighting. The clear discrepancy between our study and that in Prayitno et al. (1997) is not readily available, but it may well be likely that the behavior difference by light color would be explained by temporal and chronic stimuli as lighting period of our experiment lasted only 3 days while that of Prayitno et al. (1997) lasted 3 weeks.

In addition, our results revealed that broiler chickens showed over $70 \%$ of their behavior as resting in all LEDs used. This result is inconsistent with the result obtained by Murphy and Preston (1988) who reported that broiler chickens exhibited $61 \%$ of resting behavior regardless of lights. The difference between our study and Murphy and Preston (1988) is not readily available, but further study is warranted to reveal whether the resting behavior would be affected by the lighting types used such as LEDs, incandescent, or fluorescent lamps.

The time (expressed as percentage) spent for standing activity was higher in broiler chickens under green light $(13.43 \pm 2.30 \%)$, followed by white $(10.46 \pm 2.21 \%)$, red $(9.34 \pm 1.92 \%)$, and blue $(6.78 \pm 1.92 \%)$, however there was no marked difference among the different light colors. Pecking activity tended to be higher $(\mathrm{p}>0.05)$ in broiler chickens exposed to blue light $(16.51 \pm 3.19 \%)$, followed by white $(12.26 \pm 2.55 \%)$, green $(10.33 \pm 2.24 \%)$, and red $(9.77 \pm 3.69 \%)$. Our study is in agreement with previously reported results (Schumaier et al., 1968; North and Bell, 1993) that the level of cannibalism of birds decreased under red light. On the other hand, Prayitno (1997) showed that violence among broiler chickens increased under red light.

\section{ACKNOWLEDGMENTS}

This research was supported by Bio-industry Technology Development Program, Ministry of Agriculture, Food and Rural Affairs.

\section{REFERENCES}

Alvino, G. M., G. S. Archer, and J. A. Mench. 2009. Behavioural time budgets of broiler chickens reared in varying light intensities. Appl. Anim. Behav. Sci. 118:54-61.

Appleby, M. C., B. O. Hughes, and H. A. Elson. 1992. Poultry Production Systems: Behaviour, Management and Welfare. CAB International, Wallingford, UK.

Bizeray, D., C. Leterrier, P. Constantin, M. Picard, and J. M. Faure. 2000. Early locomotor behaviour in genetic stocks of chickens with different growth rates. Appl. Anim. Behav. Sci. 68:231242.

Blair, R., R. C. Newberry, and E. E. Gardiner. 1993. Effects of lighting pattern and dietary tryptophan supplementation on growth and mortality of broilers. Poult. Sci. 72:495-502.

Boshouwers, F. M. G. and E. Nicaise. 1987. Physical activity and energy expenditure of laying hens as affected by light intensity. Br. Poult. Sci. 28:155-163.

Buckland, R. B., D. E. Bermon, and A. Goldrosen. 1976. Effect of four lighting regimes on broiler performance, leg abnormalities and plasma corticoid levels. Poult. Sci. 55:1072-1076.

Classen, H. L., C. Riddell, and F. E. Robinson. 1991. Effects of increasing photoperiod length on performance and health of broiler chickens. Br. Poult. Sci. 32:21-29.

Hooppaw, P. D. and B. L. Goodman. 1976. The influence of intermittent light on growth performance and other traits in young chicks. Poult. Sci. 55:2285-2289.

Kjær, J. B. and K. S. Vestergaard. 1999. Development of feather pecking in relation to light intensity. Appl. Anim. Behav. Sci. 62:243-254.

Kondra, P. A. 1961. The effects of colored light on growth and feed efficiency of chicks and poults. Poult. Sci. 40:268-269.

Kristensen, H. H., N. B. Prescott, G. C. Perry, J. Ladewig, A. K. Ersboll, K. C. Overad, and C. M. Wathes. 2007. The behaviour of broiler chickens in different light sources and illuminances. Appl. Anim. Behav. Sci. 103:75-89.

Lott, B. D., S. L. Branton, and J. D. May. 1996. The effect of photoperiod and nutrition on ascites incidence in broilers. Avian Dis. 40:788-791.

MacLeod, M. G., T. R. Jewitt, and J. E. M. Anderson. 1988. Energy expenditure and physical activity in domestic fowl kept on standard and interrupted lighting patterns. Br. Poult. Sci. 29:231-244. 
Malone, G. W., G. W. Chaloupka, E. W. Walpole, and L. H Littlfield. 1980. The effect of dietary energy and light treatment on broiler performance. Poult. Sci. 59:576-581.

Mclean, J. A. and G. Tobin. 1987. Animal and human calorimetry. Cambridge University Press, Cambridge, UK. pp. 83-119.

Murphy, L. B. and A. P. Preston. 1988. Time-budgeting in meat chickens grown commercially. Br. Poult. Sci. 29:571-580.

North, M. O. and D. D. Bell. 1993. Commercial chicken production manual. 4th Ed. AVI Publishing Co., Westport, CT, USA.

Phillips, C. J. C. and D. Piggins. 1992. Environmental factors influencing the production and welfare of farm animals: Photoperiod. CAB International, Oxford, UK. pp. 49-65.

Prayitno, D. S., C. J. C. Phillips, and H. Omed. 1997. The effects of color of lighting on the behavior and production of meat chickens. Poult. Sci. 76:452-457.

Prescott, N. B. and C. M. Wathes. 1999a. Reflective properties of domestic fowl (Gallus g. domesticus), the fabric of their housing and the characteristics of the light environment in environmentally controlled poultry houses. Br. Poult. Sci. 40:185-193.
Riddell, C. and H. L. Classen. 1992. Effects of increasing photoperiod length and anticoccidials on performance and health of roaster chickens. Avian Dis. 36:491-498.

Schumaier, G., P. C. Harrison, and J. McGinnis. 1968. Effects of colored fluorescent light on growth, cannibalism and subsequent egg production of single comb White Leghorn pullets. Poult. Sci. 47:1599-1602.

Son, J. H. and R. Velmurugu. 2009. The effects of light colors on the behavior and performance of broiler chickens. Korean J. Poult. Sci. 36:329-335.

Wathes, C. M., H. H. Spechter, and T. S. Bray. 1982. The effects of light illuminance and wavelength on the growth of broiler chickens. J. Agric. Sci. (Cambridge) 98:195-201.

Widowski, T. M., L. J. Keeling, and I. J. H. Duncan. 1992. The preferences of hens for compact fluorescent over incandescent lighting. Can. J. Anim. Sci. 72:203-211.

Zulkifli, I., A. Rasedee, O. Nor Syaadah, and M. T. Che Norma. 1998. Daylength effects on stress and fear responses in broiler chickens. Asian Australas. J. Anim. Sci. 11:751-754. 